\title{
Potentiometric Determination of Amlodipine Besilate and Valsartan Using Microsized and Polymeric Matrix Membrane Sensors
}

\author{
Nesrin K. Ramadan, Heba M. Mohamed ${ }^{*}$ and Azza A. Mostafa \\ Cairo University, Faculty of Pharmacy, Analytical Chemistry Department, \\ Kasr-El-Aini 11562, Cairo, Egypt
}

Received 9 March 2011; accepted 28 Fabruary 2012

\begin{abstract}
Two poly(vinyl chloride) matrix membrane electrodes responsive to some drugs affecting the cardiovascular system, Amlodipine besilate (AM) and Valsartan (VL), were developed, described and characterized. A microsized graphite selective sensor was investigated with dibutylsebacate (DBS) as a plasticizer in a polymeric matrix of carboxylated polyvinyl chloride (PVC-COOH) in case of (sensor 1). This sensor 1 was prepared using 2 - hydroxy propyl $\beta$-cyclodextrin (2HP $\beta$-CD) as an ionophore. While sensor 2 preparation was based on precipitation technique with bathophenanthroline iron (II) as electroactive materials in poly(vinyl chloride) (PVC) matrix.

Fast and stable Nernstian responses near $1 \times 10^{-5}-1 \times 10^{-3} \mathrm{M}$ for the two drugs over the $\mathrm{pH}$ range 3-6 and 7-9 for the two sensors, respectively, were obtained. The method was successively applied for the determination of AM and VL in presence of each others, in their pharmaceutical formulations and in human plasma samples. The percentages recoveries for the determination of the drugs by the proposed selective electrodes were $99.78 \pm 0.382 \%, 100.23 \pm 0.440 \%$, for sensors 1 and 2, respectively. Statistical comparison between the results obtained by this method and those obtained by the official method and the reported method of the drugs was done and no significant difference was found.
\end{abstract}

Keywords: amlodipine besilate, valsartan, micro sensors, human plasma.

\section{Introduction}

Amlodipine besilate (AM), Fig. 1, is a long acting dihydropyridine calciumchannel blocker, that inhibits the trans membrane influx of calcium ions into

\footnotetext{
* Corresponding author. E-mail address: bebo77_7777@yahoo.com
} 
vascular smooth muscle and cardiac muscle. It is used in the management of hypertension and angina pectoris [1]. It acts by relaxing the smooth muscle in the arterial wall, decreasing total peripheral resistance and hence reducing blood pressure; in angina it increases blood flow to the heart muscle [2]. While Valsartan (VL), Fig. 1, is an angiotensin II receptor antagonist, used in the management of hypertension and may be used in patients with congestive heart failure and post myocardial infarction [1]. It also regulates the cardiovascular functions [2]. AM and VL are co-formulated together in commercial tablets as an oral anti hypertensive medication.
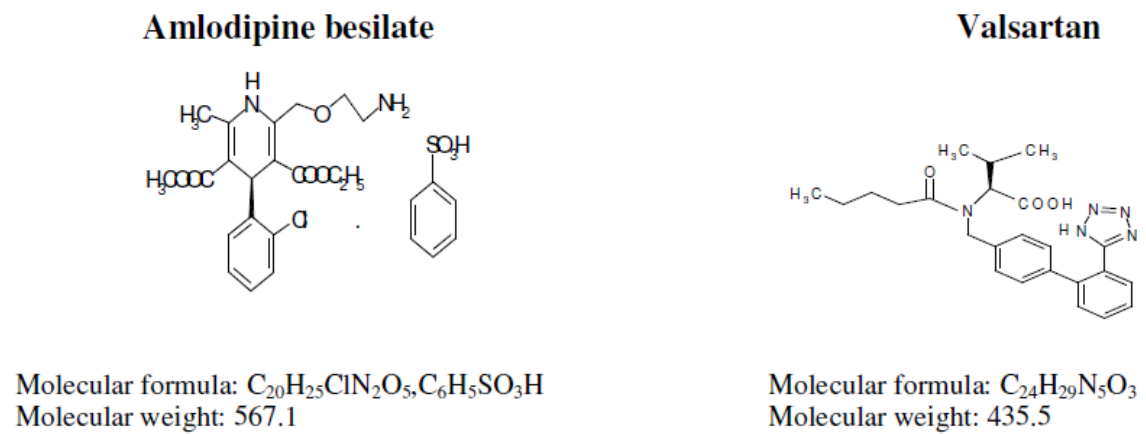

Figure 1. Chemical structures of amlodipine besilate and valsartan.

Determination of AM was described in British pharmacopoeia [3] by HPLC method. It was also determined by several methods involving spectrophotometric methods [4-11], HPLC [9, 12-15] and Densitometric TLC method [16]. While VL was determined by several methods, involving spectrophotometric [17-19], HPLC [20-25] and chemometric methods [26]. AM and VL were previously determined in their binary mixture by HPLC methods [27-29], Spectroflourimetric method [30] and TLC method [31].

No electroanalytical methods were reported for the determination of AM and VL, so the aim of the present study is to develop and validate a new potentiometric method that is simple, rapid, selective and less expensive and less time consuming compared with other published TLC and HPLC methods for the determination of AM and VL in the presence of each others, in tablets dosage form and in plasma samples without prior separation even they were present in colored, turbid and viscous solution.

Microelectrodes have been the subject of much research in recent years [32]. The advantages they offer over conventional electrodes are well known [33].

Metallic and graphite-based conductors have been suggested [34-36]; these electrodes behave as two interface devices, membrane/ electrolyte interface and membrane/metal interface [37]. Thus, the membrane potential in the cell has been considered as the electric potential difference between the two interfaces.

Membranes have been suggested to be prepared from polymer, ionophore and plasticizer. The role of the polymer is to provide an inert solid support structure in which the rest of components are embedded. The ionophore can be viewed as a molecular receptor, because its chemical structure provides well defined inclusion cavities with a specific receptor function [38]. The plasticizer used to plasticize the membrane also affects its lipophilicity. 
The microsized graphite rod was coated with a thin film of PVC-COOH / $2 \mathrm{HP} \beta-$ CD / DBS in case of sensor 1, and used as a potentiometric sensor for AM. Upon soaking this sensor in AM test solution, an acid-base interaction takes place between the dissociated $\mathrm{COO}^{-}$groups of the $\mathrm{PVC}$ and the amino group of the drug, and a homogenous electroactive layer from PVC-COOH / 2HP $\beta-C D$ / DBS / Drug is formed, which induces a potentiometric response for the studied drug.

For sensor 2, VL-BP iron (II) complex was embedded in a PVC matrix membrane which acts as a regular support and reproducible trap for ion association complexes in ISEs and placticized with DBS as suitable solvent mediator.

\section{Experimental}

\section{Apparatus}

- Jenway digital ion analyzer model 3330 (UK) with $\mathrm{Ag} / \mathrm{AgCl}$ double junction reference electrode no. Z113107-1EAPW (Aldrich Chemical Co.).

- pH glass electrode Jenway (Jenway, UK) no. 924005-BO3-Q11C.

- Magnetic stirrer, Bandelin Sonorox, Rx510S (Budapest,Hungarian).

\section{Reference samples}

Amlodipine besilate (AM) and Valsartan (VL)-Pure samples were kindly supplied by Global Nabi Co., batch numbers 80148 and 4705, respectively, (Giza - Egypt). Their percentages purity were $99.75 \pm 0.360 \%$ and $100.50 \pm 0.387 \%$; respectively, according to the official method for AM [3] and reported method for VL [20].

\section{Pharmaceutical formulations}

- Exforge 10/160 tablets-Batch number y0001/s0009. Each tablet is claimed to contain $10 \mathrm{mg}$ of AM and $160 \mathrm{mg}$ of VL. Manufactured by: Novartis pharma, (Cairo, Egypt).

- Exforge 5/80 tablets-Batch number F0030. Each tablet is claimed to contain 5 $\mathrm{mg}$ of AM and $80 \mathrm{mg}$ of VL. Manufactured by: Novartis pharma, (Cairo, Egypt).

\section{Reagents}

All chemicals and solvents used were of analytical grade (the used water was double distilled). All chemicals and solvents used were handled in the fuming cupboard, wearing gloves and masks and the measure of the solvents was done using pipettes with the aid of a pipette filler.

Polyvinyl chloride carboxylated (PVC-COOH); (Fluka chemie GmbH Germany). Dibutylsebacate (DBS) - (Sigma/Aldrich, St.Louis, MO).

2-Hydroxy propyl B-Cyclodextrin (2HP $\beta$-CD); (Fluka Chemie GmbH, Germany).

Tetrahydrofuran (THF) - (BDH, limited Poole, England). 
Sodium hydroxide, $1 \mathrm{M}$ aqueous solution; (Prolabo, VWR International, West Chester, PA).

Hydrochloric acid, $1 \mathrm{M}$ aqueous solution; (Prolabo, VWR International, West Chester, PA).

Acetate buffer $\mathrm{pH} 3.0$ and phosphate buffer $\mathrm{pH}$ 8.0.

Bathophenanthroline (BP); (Merck, Darmstadt, Germany).

Bathophenanthroline iron (II), (BP iron II) complex, prepared by dissolving 100 $\mathrm{mg}$ of bathophenanthroline in $20 \mathrm{~mL}$ of $10^{-2} \mathrm{M}$ iron (II) ammonium sulfate, followed by drops of ethanol and $\mathrm{H}_{2} \mathrm{O}$ to keep a clear solution.

\section{Standard solutions}

- AM and VL stock solutions $\left(1 \times 10^{-2} \mathrm{M}\right)$

They were prepared by transferring 0.567 of $\mathrm{AM}$ in $100 \mathrm{~mL}$ acetate buffer $\mathrm{pH} 3$ and $0.435 \mathrm{~g}$ VL in $100 \mathrm{~mL}$ phosphate buffer $\mathrm{pH} 8$.

- $A M$ and VL working solutions $\left(1 \times 10^{-5}\right.$ to $\left.1 \times 10^{-3} \mathrm{M}\right)$

They were prepared by proper dilution from their stock solutions using either acetate buffer in case of AM or phosphate buffer in case of VL.

\section{Laboratory prepared mixtures containing different ratios of $A M$ and $V L$}

Into two series of $25 \mathrm{~mL}$ volumetric flasks, different volumes of AM (1 mg/mL) and VL $(5 \mathrm{mg} / \mathrm{mL})$ were accurately transferred. Then the volume was completed with acetate buffer for determination of $\mathrm{AM}$ and the other series with phosphate buffer for determination of VL to prepare mixtures containing different ratios of the two drugs for the proposed sensors.

\section{Procedures}

Preparation of electroactive coating membranes: $(2-H P \beta-C D / D B S / P V C$ $\mathrm{COOH})$, and sensor 1 fabrication

In a glass Petri dish (5 cm diameter), a portion of $0.9 \mathrm{gm} \mathrm{PVC-COOH}$ was thoroughly mixed with $0.35 \mathrm{gm}$ DBS and $0.3 \mathrm{gm} 2-\mathrm{HP} \beta-\mathrm{CD}$, then dissolved in $15 \mathrm{~mL}$ THF. The Petri dish was covered with a filter paper and left to stand for 1 $\mathrm{h}$ to allow slow solvent evaporation. A thick homogeneous solution was produced which was used for preparation of sensor 1 .

A rod of spectrographic graphite $(5 \mathrm{~mm}$ in diameter and $15 \mathrm{~mm}$ long) was inserted in a polyethylene sleeve, and about $3 \mathrm{~mm}$ of the other end of the protruded rod served as a measuring surface. This end of the rod was washed with acetone, dried in air for 3 hours, and dipped rapidly into the previously prepared PVC-COOH / 2-HP $\beta-\mathrm{CD} / \mathrm{DBS}$ solution. The solvent was allowed to evaporate in air after each dipping, and the dipping process was repeated 6-8 times to produce a uniform membrane on the surface of the graphite rod. Drops of mercury were added in the polyethylene sleeve to ensure electrical contact with the connection cable. The coated graphite rod was conditioned by soaking in a $10^{-2} \mathrm{M}$ AM solution for 4 hours, and stored in the same solution when not in use. 
Precipitation based technique for sensor 2 fabrication

VL-BP iron (II) ion pair complex was prepared by mixing $10 \mathrm{~mL}$ of $10^{-2} \mathrm{M}$ ammoniacal aqueous solution of VL (on which 2 drops of $30 \% \mathrm{NH}_{3}$ solution were added to enhance solubility) with $20 \mathrm{~mL} 10^{-2} \mathrm{M}$ BP-iron (II) solution for preparation of electrode 2 .

The resulting precipitate formed was filtered using Whatmann No. 42 papers, washed with cold water, dried at room temperature (about $20{ }^{\circ} \mathrm{C}$ ) and grinded to fine powder.

Elemental analysis of the formed complexes confirmed the formation of drug: ion exchanger in the ratio of 2:1 in case of sensor 2 .

A portion $(10 \mathrm{mg})$ of VL-ion exchanger was thoroughly mixed with $0.19 \mathrm{~g}$ PVC and $0.35 \mathrm{~mL}$ DBS in a glass Petri dish $(5 \mathrm{~cm}$ diameter) then dissolved in $5 \mathrm{~mL}$ THF. The Petri dish was covered with filter paper and left to stand overnight to allow solvent evaporation at room temperature. Master membrane with thickness of $0.1 \mathrm{~mm}$ was obtained and used for the construction of the sensor 2 [39-41].

Equal volumes of $10^{-2} \mathrm{M} \mathrm{VL}$ and $10^{-2} \mathrm{M} \mathrm{KCl}$ were mixed and this solution was used as internal reference solution. $\mathrm{Ag} / \mathrm{AgCl}$ wire $(1 \mathrm{~mm}$ diameter) was immersed in the internal reference solution as internal reference electrode.

The electrode was conditioned by soaking in $1 \times 10^{-2} \mathrm{M} \mathrm{VL}$ aqueous solution for one day and was stored in the same solution when not in use.

Direct potentiometric determination of the drugs in their pure samples

The prepared electrodes in conjunction with the double junction $\mathrm{Ag} / \mathrm{AgCl}$ reference electrode were immersed in aqueous solutions of AM and VL in the range of $\left(1 \times 10^{-5}-1 \times 10^{-3} \mathrm{M}\right)$ in case of sensor 1 and 2 . They were allowed to equilibrate while stirring and the emfs were recorded within $\pm 1 \mathrm{mV}$. The membrane sensors were washed with double distilled water between measurements. Calibration graphs were plotted relating the recorded potentials vs. - log drug concentrations, regression equations were computed and used for subsequent measurements of unknown concentrations of AM and VL.

Identification of the slope, response time and operative life of the studied electrodes

The electrochemical performance of the two proposed sensors was evaluated according to the IUPAC recommendations data [42].

The dynamic response times for the electrodes to reach values of $\pm 1 \mathrm{mV}$ of the final equilibrium potential after increasing the drug concentration 10 folds were measured.

\section{Effect of $p H$}

The effect of $\mathrm{pH}$ on the potential values of the two electrodes was studied over $\mathrm{pH}$ range from 2 to 11 by adding drops of $1 \mathrm{~N} \mathrm{HCl}$ and $1 \mathrm{~N} \mathrm{NaOH}$ on the aqueous solutions of both drugs, and the potentials obtained at each value were recorded. 


\section{Effect of temperature}

The effect of temperature was studied, and the potential response displayed by the investigated electrodes as a function of temperature in the range of $20^{\circ}-40^{\circ} \mathrm{C}$ was monitored. The potentials obtained at each temperature were recorded.

\section{Effect of interfering compounds on the electrode selectivity}

The potential response of the two studied sensors in the presence of the drugs and a number of related substances was studied, and the potentiometric selectivity coefficient, - $\log \left(\mathrm{K}^{\mathrm{Pot}}\right.$ Primary ion, interferernt $)$ was used to evaluate the extent to which a foreign ion would interfere with the response of the electrodes to its primary ion. The selectivity coefficients were calculated by the separate solutions method (SSM) [40], where potentials were measured for $10^{-3} \mathrm{M}$ drug solution and then for $10^{-3} \mathrm{M}$ interferent solution, separately, then potentiometric selectivity coefficients were calculated using the following equation:

$$
\text { - } \log \left(K_{\text {primary ion interferent }}^{\text {pot }}\right)=E_{1}-E_{2} / S
$$

where $E_{1}$ is the potential measured in $10^{-3} \mathrm{M}$ solution of the $1^{\mathrm{ry}}$ ion solution, $\mathrm{E}_{2}$ the potential measured in $10^{-3} \mathrm{M}$ solution of interferent and $\mathrm{S}$ is the slope of the investigated sensor.

\section{Analysis of laboratory prepared mixtures}

The potential readings produced by immersing the prepared electrodes in conjunction with the double junction $\mathrm{Ag} / \mathrm{AgCl}$ reference electrode in the prepared mixtures [2.6.] were recorded and compared with the calibration graphs.

Application of the proposed method for simultaneous determination of AM and $V L$ in exforge tablets

Ten tablets of the drug formulations were weighed accurately and finely powdered in a small dish. An amount of powder equivalent to $56.7 \mathrm{mg}$ of AM from the two formulations was accurately transferred to $100 \mathrm{~mL}$ volumetric flasks and diluted to the mark with acetate buffer $\mathrm{pH} 3$ to prepare $10^{-3} \mathrm{M}$ solutions of AM. Another amount of powder equivalent to $43.5 \mathrm{mg}$ of VL from the two formulations was accurately transferred to $100 \mathrm{~mL}$ volumetric flasks and diluted to the mark with phosphate buffer $\mathrm{pH} 8$ to prepare $10^{-3} \mathrm{M}$ solutions of VL. The potential readings produced by immersing the prepared electrodes in conjunction with the double junction $\mathrm{Ag} / \mathrm{AgCl}$ reference electrode in the prepared solutions were recorded and compared with the calibration graphs.

Direct potentiometric determination of $A M$ and $V L$ in spiked human plasma sample

Portions equivalent to $4.5 \mathrm{~mL}$ of human plasma were placed into four stoppered shaking tubes, and then $0.5 \mathrm{~mL}$ of $10^{-2}$ and $10^{-3} \mathrm{M} \mathrm{AM}$ and $0.5 \mathrm{~mL}$ of $10^{-2}$ and $10^{-3} \mathrm{M}$ VL were added separately and shacked. The membrane sensors were immersed in conjunction with the $\mathrm{Ag} / \mathrm{AgCl}$ reference electrode in these solutions. The membrane sensors were washed with water between measurements. The potential readings produced by immersing the prepared electrodes in conjunction 
with the double junction $\mathrm{Ag} / \mathrm{AgCl}$ reference electrode in the prepared solutions were recorded and compared with the calibration plots. No adverse effect on the responses of the electrodes was observed when the drugs were spiked with the human plasma samples without prior removal of the protein.

\section{Results and discussion}

The preparation and application of microelectrodes have attracted much interest in recent analytical chemistry studies [32]. This is part of a general trend in analytical chemistry towards miniaturization. The features of voltammetric microelectrodes have been investigated extensively during the last few years with the aim of improving the characteristics of electrochemical methods and performing studies under conditions not possible with conventional electrodes $[43,44]$. A variety of electrode materials of different shapes and sizes have been reported, but the most commonly used electrode materials are platinum [45] and carbon fiber[46].

On the other hand, VL behaves as anion, suggesting the use of ion exchangers of cationic types and the formation of classic type of membrane electrodes.

\section{Sensors fabrication}

In the present work, the microsized graphite rod was coated with a thin film of PVC-COOH / 2-HP $\beta$-CD / DBS for sensor 1 and used as a potentiometric sensor for AM. Upon soaking this sensor in $1 \times 10^{-2} \mathrm{M}$ AM test solution, a homogenous electroactive layer from PVC-COOH / 2-HP $\beta-\mathrm{CD} / \mathrm{DBS} / \mathrm{AM}$ in case of sensor 1 was formed which induces a potentiometric response for the studied drug. While for sensor 2, a homogenous electroactive layer from ion-pair complex (VL-BP ironII) / DBS / VL is embedded in a PVC matrix membrane and plasticized with DBS as plasticizer.

\section{DBS (a non polar plasticizer)}

DBS was found to be the optimum available mediator for both membrane sensors. It plasticizes the membrane and adjusts the membrane permittivity to give the highest possible selectivity and sensitivity.

\section{Cyclodextrins}

The molecular recognition and inclusion complexation are of current interest in host-guest chemistry or supramolecular chemistry [47]. Natural and chemically modified cyclodextrins, can be viewed as molecular receptors because their chemical structure provides well defined inclusion cavities with a specific receptor function. They can accommodate a wide variety of organic, inorganic, and biological guest molecules to form stable host-guest inclusion complexes or nanostructure supramolecular assemblies in their hydrophobic cavity, showing high molecular selectivity and enantioselectivity [48].

Although the size and geometry of the guest mainly govern the binding strength, it is possible to influence the host-guest interactions by modification of the three 
hydroxyl groups on each glucose unit; hence the use of 2-HP $\beta$-CD proved to enhance the interaction properties between host and guest molecules [49].

The possibility of using functionalized lipophilic CD derivatives (2-HP $\beta$-CD) as the sensor ionophore in the preparation of AM selective electrode (sensors 1) with PVC-COOH to immobilize the sensor and to attain the formation of highly stable complex was evaluated. Also 2 -HP $\beta$-CD has better aqueous solubility (up to $0.7 \mathrm{M})$ than $\beta-\mathrm{CD}$ which is poorly soluble in water $(0.02 \mathrm{M})$ [50], so it was preferred to use 2-HP $\beta-\mathrm{CD}$ as an ionophore, which provides high stability of the complex between the molecule and the cationic drug present in solution, in addition to enhancing the membrane selectivity and sensitivity.

\section{$\mathrm{PVC}-\mathrm{COOH}$}

PVC-COOH was used because of its recommended properties which are the partial dissociation and the high adhesion [51]; sensor 1 was simply fabricated without the need of ion association complex. It was only preconditioned by soaking in the corresponding drug solution for 4 hours where acid-base interactions take place between the dissociated $\mathrm{COO}^{-}$group of the $\mathrm{PVC}$ and tertiary amino group of the drug in the test solution until chemical equilibrium is attained.

PVC-COOH also acts as a regular support matrix, as trap for the ion and as polymeric matrix to immobilize the sensor and to attain the formation of highly stable complex.

\section{BP-ironII}

The present study originates from the fact that VL behaves as anion due to the presence of $\mathrm{COO}^{-}$acid group [39]. This fact suggests the use of ion exchanger of cationic type. It has been found that bathophenanthroline iron II is the optimum cationic exchanger of VL for its low solubility product, high lipophilicity and suitable grain size. So (VL-BP ironII) is embedded in PVC matrix membrane and plasticized with DBS as plasticizer.

Sensors calibration and response time

Electro chemical performance characteristics of the proposed sensors were systematically evaluated according to IUPAC standards [42].

Table 1 shows the results obtained over a period of four weeks for each sensor. Typical calibration plots are shown in Fig. 2. The sensors displayed constant potential readings within $\pm 2 \mathrm{mV}$ from day to day and the calibration slopes did not change by more than $\pm 2 \mathrm{mV}$ per decade over a period of 4 weeks for both sensors.

The required time for the sensors to reach values within $\pm 2 \mathrm{mV}$ of the final equilibrium potential after increasing drug concentration 10-folds was found to be 10-20 and 20-30 seconds, for sensors 1 and 2, respectively. The slopes of the calibration plots were 26.8 and $56.4 \mathrm{mV} /$ concentration decades for sensor 1 and 2 , respectively, the typical values of divalent and monovalent substances as AM behaves as divalent cation via its amino groups, and VL behaves as a monovalent anion via its carboxylic acid group. Deviation from the ideal Nernstian slope (30 
$\mathrm{mV} /$ decade and $60 \mathrm{mV} /$ decade) for sensors 1 and 2 , is originated from the fact that the electrodes respond to the activities of the drug rather than its concentrations.

Table 1. Response characteristics of the two investigated selective electrodes and the validation parameters of the response and the regression equations.

\begin{tabular}{|c|c|c|}
\hline \multirow[t]{2}{*}{ Parameter } & \multicolumn{2}{|c|}{ Value } \\
\hline & Sensor 1 & Sensor 2 \\
\hline $\begin{array}{l}\text { Validation of the regression equations } \\
\text { Slope }\left(\mathrm{mV} / \mathrm{decade}^{\mathrm{a}}\right. \\
\text { Intercept }(\mathrm{mV})^{\mathrm{a}} \\
\text { Correlation coefficient (r) } \\
\text { Validation of the responses } \\
\text { Concentration range (M) } \\
\text { Response time (s) } \\
\text { Working pH range } \\
\text { LOD (M) } \\
\text { Stability (weeks) } \\
\text { Average accuracy (\%) } \\
\text { Standard deviation (precision) } \\
\text { Relative standard deviation (precision \%) } \\
\text { Repeatability }{ }^{\mathrm{c}}(\%) \\
\text { Intermediate precision }{ }^{\mathrm{d}}(\%)\end{array}$ & $\begin{array}{c}26.8 \pm 0.45 \% \\
384.2 \pm 0.55 \% \\
0.9998 \\
1 \times 10^{-5}-1 \times 10^{-3} \\
10-20 \\
3-6 \\
7.5 \times 10^{-6} \\
4 \\
99.78 \\
0.382 \\
0.382 \\
0.320 \\
0.641\end{array}$ & $\begin{array}{c}56.4 \pm 0.3 \% \\
135.2 \pm 0.42 \% \\
0.9999 \\
1 \times 10^{-5}-1 \times 10^{-3} \\
20-30 \\
7-9 \\
8.3 \times 10^{-6} \\
4 \\
100.23 \\
0.442 \\
0.440 \\
0.462 \\
0.508\end{array}$ \\
\hline Specificity (\%) & $100.79 \pm 0.530 \%$ & $99.64 \pm 0.636 \%$ \\
\hline
\end{tabular}

a Results of five determinations; ${ }^{b}$ The lower detection limit (LOD) defined as drug concentration obtained at the intersection of the extrapolated high concentration (linear segment) with the low concentration (zero slope segment) of the calibration plot. ${ }^{c} n=3 \times 3 .{ }^{d} n=3 \times 3$

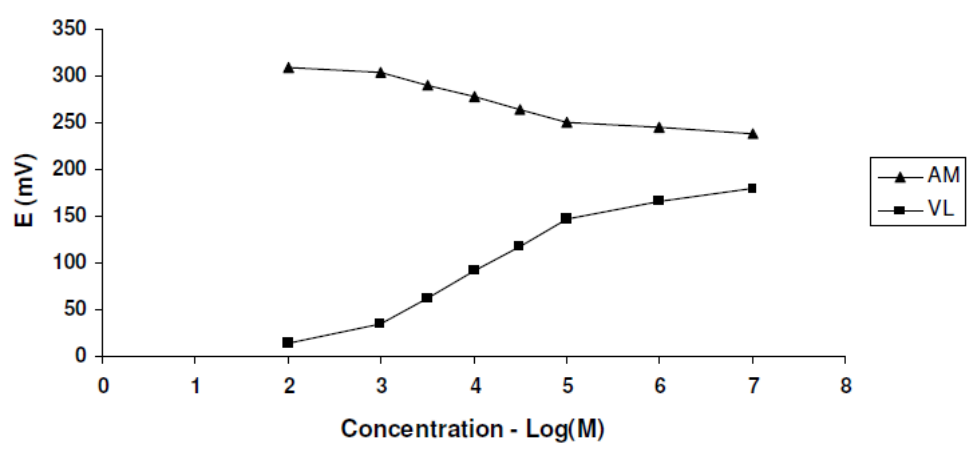

Figure 2. Profiles of the potential in $\mathrm{mV} /$ - Log concentration in $(\mathrm{M})$ of $\mathrm{AM}$ using $\mathrm{AM} / \mathrm{PVC}-\mathrm{COOH} / 2 \mathrm{HP} \beta-\mathrm{CD}$ (sensor 1) and of VL using VL-BP-iron (II) (sensor 2).

\section{Effect of $\mathrm{pH}$ and temperature}

In the measurements with the two investigated sensors, the different factors affecting the response of the electrodes (emfs) were studied to reach the optimum experimental conditions. $\mathrm{pH}$ values within the range (3-6) and (7-9) were found to be optimum from the point of view of sensor 1 and 2, respectively. AM was in the cationic form in acidic media and VL in the anionic form in alkaline media. Fig. 3 shows the potential $\mathrm{pH}$ profile for $10^{-3}$ and $10^{-4} \mathrm{M}$ drug solutions. For sensor $1 \mathrm{pH}$ above 6 , the potentials displayed by the sensor decreased due to the 
formation of non-protonated amino group of $\mathrm{AM}$ drug; below $\mathrm{pH} 3$, the potentials displayed by the sensor were noisy and unbalanced. In case of sensor 2, at $\mathrm{pH}$ below 7 the potentials displayed by the sensor decreased with the increase of solution acidity; at such high acidity the dissociation of the carboxyl group is limited and the membrane may extract $\mathrm{H}^{+}$, leading to noisy responses; above $\mathrm{pH} 9$, the potentials displayed by the sensor were noisy and unbalanced. It is apparent that the sensors responses are fairly constant in solutions of $\mathrm{pH} 3-6$ for sensor 1 so AM was dissolved in acetate buffer $\mathrm{pH} 3$, and $\mathrm{pH}$ 7-9 for sensor 2 , so VL was dissolved in phosphate buffer $\mathrm{pH} 8$.

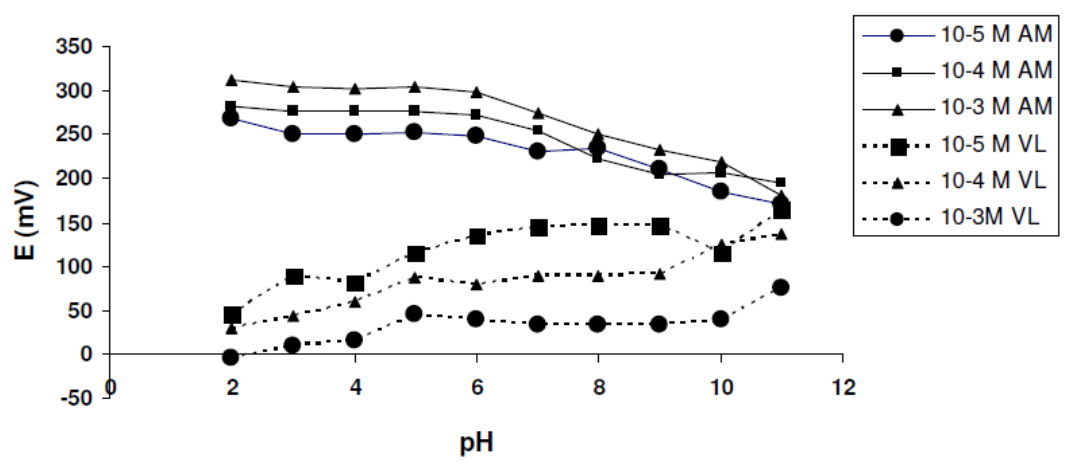

Figure 3. Effect of $\mathrm{pH}$ on both the responses of AM/PVC-COOH/2HP $\beta-\mathrm{CD}$ (sensor 1) and of VL-BP-iron (II) (sensor 2).

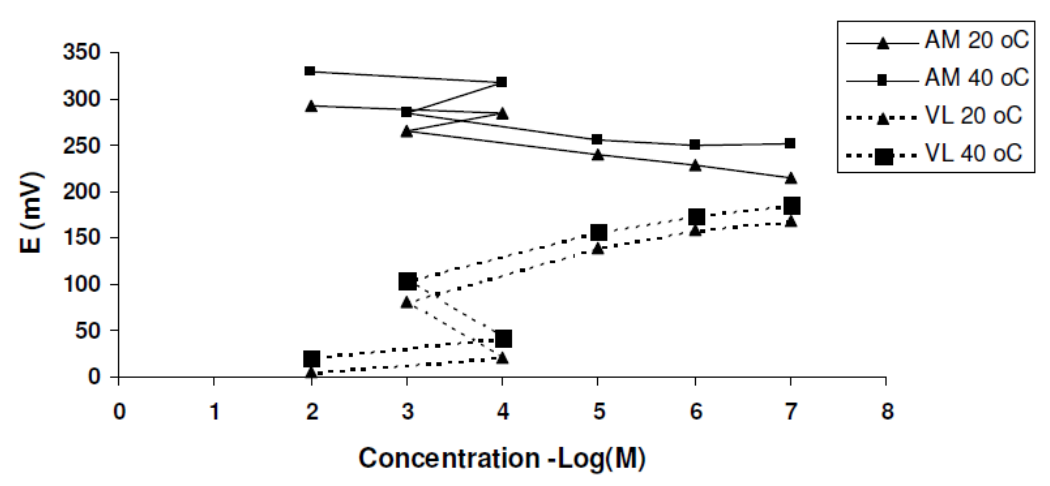

Figure 4. Effect of temperature on both the responses of AM/PVC-COOH/2HP $\beta-\mathrm{CD}$ (sensor 1) and of VL-BP-iron (II) (sensor 2).

Upon studying the effect of temperature, the suggested sensors exhibit slight gradual increase in their potentials as the temperature increases in the range of 20-40 ${ }^{\circ} \mathrm{C}$; however, the calibration graphs obtained at different temperatures were parallel, slope and response time did not significantly vary with variation of temperature indicating reasonable thermal stability of the suggested sensors up to $40{ }^{\circ} \mathrm{C}$, Fig. 4.

\section{Sensors selectivity}

The effect of interfering substances upon the performance of the sensors was studied by separate solutions method [40].

The performance of the two sensors in the presence of tablets excipients, organic and inorganic related substances were assessed by measuring and comparing the 
potentiometric selectivity coefficients. The results revealed that the proposed membrane sensors displayed high selectivity compared to the reported HPLC methods, which can highly be affected by the excipients and related substances of the drugs. No significant interference was observed from interfering species (Table 2).

Table 2. Potentiometric selectivity coefficients $\left(\mathrm{K}^{\mathrm{pot}}{ }_{1 \mathrm{ry} \text { ion }}\right)$ of the two proposed sensors.

\begin{tabular}{|c|c|c|}
\hline Interferent* $^{*}$ & Sensor (1) & Sensor (2) \\
\hline $\mathrm{NH}_{4} \mathrm{Cl}$ & $6.73 \times 10^{-4}$ & $4.64 \times 10^{-4}$ \\
$\mathrm{NaCl}$ & $4.77 \times 10^{-4}$ & $4.27 \times 10^{-4}$ \\
$\mathrm{KCl}$ & $3.02 \times 10^{-4}$ & $3.94 \times 10^{-4}$ \\
$\mathrm{CaCl}_{2}$ & $8.71 \times 10^{-4}$ & $6.17 \times 10^{-4}$ \\
Glucose & $7.33 \times 10^{-4}$ & $8.20 \times 10^{-4}$ \\
Lactose & $9.49 \times 10^{-4}$ & $6.98 \times 10^{-4}$ \\
Starch & $1.20 \times 10^{-4}$ & $3.20 \times 10^{-4}$ \\
Talc & $1.31 \times 10^{-4}$ & $3.63 \times 10^{-4}$ \\
$\mathrm{Urea}$ & $1.59 \times 10^{-3}$ & $1.00 \times 10^{-3}$ \\
$\mathrm{AM}$ & ------ & $1.85 \times 10^{-3}$ \\
$\mathrm{VL}$ & $5.29 \times 10^{-3}$ & ------ \\
\hline
\end{tabular}

* Average of 3 determinations. All interferents are in the form of $1 \times 10^{-3} \mathrm{M}$ solution.

To evaluate precision and accuracy, three concentrations within the linear range $\left(10^{-5}, 10^{-4}\right.$ and $10^{-3} \mathrm{M}$ solutions of AM and VL) were chosen. Three solutions of each concentration were prepared and analyzed in triplicate (repeatability assay). This assay was repeated on three different days (intermediate precision assay), (Table 1).

Table 3. Determination of intact AM and VL in laboratory prepared mixtures by the proposed potentiometric method.

\begin{tabular}{|c|c|c|c|c|}
\hline \multirow{3}{*}{$\begin{array}{c}\text { Ratio } \\
\text { AM:VL }\end{array}$} & \multirow{3}{*}{$\begin{array}{c}\mathrm{AM} \\
(\mathrm{mg} / \mathrm{mL})\end{array}$} & \multirow{3}{*}{$\begin{array}{c}\mathrm{VL} \\
(\mathrm{mg} / \mathrm{mL})\end{array}$} & \multicolumn{2}{|c|}{ Recovery \% } \\
\hline & & & AM & VL \\
\hline & & & Sensor (1) & Sensor (2) \\
\hline $1: 16$ & 0.1 & 1.6 & 101.24 & 99.12 \\
\hline $1: 14$ & 0.1 & 1.4 & 100.84 & 99.82 \\
\hline $1: 12$ & 0.1 & 1.2 & 100.90 & 100.19 \\
\hline $2: 16$ & 0.2 & 1.6 & 101.08 & 100.23 \\
\hline $1.5: 10$ & 0.3 & 2.0 & 99.87 & 98.83 \\
\hline \multicolumn{3}{|c|}{ Mean } & 100.79 & 99.64 \\
\hline \multicolumn{3}{|c|}{ R.S.D.\% } & 0.530 & 0.636 \\
\hline
\end{tabular}

Table 3 shows the results obtained upon the analysis of synthetic mixtures containing different ratios of AM and VL. The results showed that sensor 1 can be successfully used for selective determination of AM in presence VL, and sensor 2 can be successfully used for selective determination of VL in presence of AM. 
Table 4. Determination of AM and VL in pharmaceutical formulations by the suggested potentiometric procedure.

\begin{tabular}{|c|c|c|}
\hline Sensors & Pharmaceutical formulations & Found $^{\text {a }} \% \pm$ R.S.D. $\%$ \\
\hline Sensor 1 & $\begin{array}{l}\text { Exforge tablets }(10 / 160 \mathrm{mg}) \\
\text { B.N. y0001/s0009 } \\
\text { Exforge tablets }(5 / 80 \mathrm{mg}) \\
\text { B.N. F0030 }\end{array}$ & $99.40 \pm 0.161$ \\
\hline Sensor 2 & $\begin{array}{l}\text { Exforge tablets }(10 / 160 \mathrm{mg}) \\
\text { B.N. y0001/s0009 } \\
\text { Exforge tablets }(5 / 80 \mathrm{mg}) \\
\text { B.N. F0030 }\end{array}$ & $\begin{array}{l}100.84 \pm 0.229 \\
98.87 \pm 0.370\end{array}$ \\
\hline
\end{tabular}

Table 4 shows the results obtained for the determination of AM and VL in exforge tablets, proving the applicability of the method without prior treatment or separation, like other reported methods, using the two sensors for the determination of $\mathrm{AM}$ and $\mathrm{VL}$, as demonstrated by the accurate and precise percentage recovery.

Table 5. Determination of AM and VL drugs in spiked human plasma by the proposed electrodes.

\begin{tabular}{|c|c|c|}
\hline \multirow{2}{*}{ Concentration (M) } & \multicolumn{2}{|c|}{ Recovery $^{\mathbf{a}} \% \mathbf{\text { R.S.D. }}$} \\
\cline { 2 - 3 } & Sensor 1 & Sensor 2 \\
\hline $1 \times 10^{-3}$ & $99.12 \pm 0.44 \%$ & $98.82 \pm 0.64 \%$ \\
\hline $1 \times 10^{-4}$ & $100.54 \pm 0.49 \%$ & $100.33 \pm 0.43 \%$ \\
\hline
\end{tabular}

${ }^{\text {a }}$ Average of three determinations.

Table 5 shows the results obtained for the determination of AM and VL in spiked human plasma. It is seen that high accuracy (recovery) and precision (RSD) were given by both sensors without prior treatment to the samples; this shows that the efficacy of the sensors has not been affected by the plasma proteins.

The results obtained were also compared with those obtained by using official method for AM [3] and the reported method for VL [20]. No significant difference in results was found, (Table 6).

Table 1 shows all the validation parameters of the proposed method, including linearity, range and LOD, which proves the accuracy, precision and sensitivity of the proposed method.

The proposed potentiometric method shows high degree of accuracy, precision, sensitivity and selectivity; furthermore, it is less expensive and less time consuming compared to other HPLC and TLC methods, being applicable in colored, turbid and viscous solutions of the drugs [52]. 
Table 6. Statistical analysis between the results obtained for the determination of AM and VL drugs in pure samples by the proposed methods and those obtained by the official and the reported methods.

\begin{tabular}{|c|c|c|c|c|}
\hline Item & Electrode 1 & $\begin{array}{c}\text { Official method }^{(3)^{*}} \\
\text { for AM }\end{array}$ & Electrode 2 & $\begin{array}{c}\text { Reported } \\
\text { method }^{(20) * *} \text { for VL }\end{array}$ \\
\hline Mean & 99.78 & 99.75 & 100.23 & 100.50 \\
S.D. & 0.382 & 0.359 & 0.442 & 0.389 \\
RSD\% & 0.382 & 0.360 & 0.440 & 0.387 \\
Variance & 0.146 & 0.129 & 0.195 & 6 \\
n & 5 & 6 & $1.291(5.19)^{*}$ & \\
F test & $1.132(5.19)^{*}$ & & $1.079(2.262)^{*}$ & \\
Student's t & $0.134(2.262)^{*}$ & & & \\
test & & & \\
\hline
\end{tabular}

Figures between parenthesis are the corresponding tabulated values $(\mathrm{P}=0.05) .{ }^{(3)}$ HPLC method using (acetonitrile: methanol: solution of $7 \mathrm{ml}$ triethylamine in a liter of water, $\mathrm{pH} 3$ with phosphoric acid 15: 35:50 by volume). ${ }^{(20)}$ HPLC method using ( $0.02 \mathrm{M}$ phosphate buffer $\mathrm{pH} 3.2$ : acetonitrile 55:45 v/v)

\section{Conclusions}

The described sensors are sufficiently simple and selective for the quantitative determination of AM and VL in pure form, in presence of each others, in plasma and pharmaceutical formulations. The use of the proposed sensors offers advantages of fast response and elimination of drug pretreatment or separation steps. They can therefore, be used for routine analysis of AM and VL in quality control laboratories.

\section{References}

1. S.C. Sweerman, Martindale, The Complete Drug Reference, 32 ED., The Pharmaceutical Press, London, UK, 2004, pp 862, 1018.

2. J.C. Garrisor, Goodman \& Gillman's, The Pharmacological Basis of Therapeutics. Hardman, J.G., Limbird, L.E. $10^{\text {th }}$ Ed., McGraw-Hill, Dallas, Taxas, USA, 2001, pp 857, 894.

3. British Pharmacopoeia, Her Majesty's Stationary Office, London., 2004, pp 124-125, 2604.

4. M.D. Malesuik, S.G. Cardoso, L . Bajerski, A. Lanzanova, J. AOAC 89(2) (2006) 359-364.

5. $\quad$ S.A. Khopade, N.K.Jain, Indian Drugs 37 (2000) 351-353.

6. H.K. Jain, R.K. Agrawal, Indian Drugs 37 (2000) 196-199.

7. R.T. Sane, M. Phadke, P.S. Hijii, M. Shah, P.H. Patel, Indian Drugs 35 (1998) 79-85.

8. $\quad$ S. Singh , R. Jain, Indian Drugs 34 (1997) 678-679.

9. S.B. Wankhede, S.B. Wadkar, K.C. Raka and S.S. Chitlange, Ind. J. Pharm. Sci. 71 (2009) 563-567.

10. P. Rathee, S. Rathee, S. Thakur, V. Kumar, Int. J. Chem. Tech. Res. 2 (2010) 62-68

11. V.C. Chandnani, K.R. Gupta, C.T. Chopde, H.K. Kunjwani, A.M. Manikrao, S.C. Shivhare, Int. J. Chem. Tech. Res. 2 (2010) 69-73. 
12. J. Bhatt, S. Singh, B. Shah, S. Kambli and S. Ameta, Biomed. Chromatogr. 21 (2007) 169-175.

13. C.P. Li, X.P. Yan, W.G. Shan, Yaowu Fenxi Zazhi 26 (2006) 1878-1879.

14. Y.Y. Ma, F. Qin, X.H. Sun, F.M. Li, J. Pharm. Biomed. Anal. 43 (2007)1540-1545.

15. R.P. Priyanka, U.R. Sachin, P.N. Dhabale, K.B. Burade, Int. J. Chem. Tech. Res. 1 (2009) 464-469.

16. N.R. Vekariya, G.F. Patel, H.S. Bhatt, M.B. Patel, R.B. Dholakiya, G.K. Ramani, Int. J. Chem. Tech. Res. 1 (2009) 1644-1649.

17. S. Tatar, S. Saglik, J. Pharm. Biomed. Anal. 30 (2002) 371-375.

18. E. Dinc, B. Uslu, S.A. Ozkan, Anal. Lett. 37 (2004) 679-693.

19. K.R. Gupta, A.R. Wadodkar, S.G. Wadodkar, Int. J. Chem. Tech. Res. 2 (2010) 985-989.

20. E. Santana, S. Altinay, N. Goger, Z. Senturk, J. Pharm. Biomed. Anal. 25 (2001) 1009.

21. J. Mac, J. Klíma, P. Ptáček, J. Chromatogr. B 832 (2006) 169-172.

22. B.K.-Kaymakcoglu, S. Unsalan and S. Rollas, Die Pharmazie 61 (2006) 586-589.

23. N. Ferreiros, G. Iriarte, R.M. Alonso, J. Sep. Sci. 31 (2008) 667-676.

24. D. Ivanovic, A. Malenovic, B. Janaic, B. Medenica, J. Liq. Chromatogr. 30 (2007) 2879-2890.

25. Ch. Krishnaiah, A.R. Reddy, R. Kumar, K. Mukkanti, J. Pharm. Biomed. Anal. 53 (2010) 483-489.

26. N. Erk, Anal. Lett. 35 (2002) 238.

27. S.S. Chitlange, B. Kiran, D.M. Sakarkar, Asian J. Res. Chem. 1 (2008) 1518.

28. D. Kull, T. Dogan, B.Opal, T. Kutucu, B.Uslu, S.A.Ozkan, J.AOAC Int. 93 (2010) 882-890.

29. N.K. Ramadan, H.M. Mohamed, A.A. Moustafa, Anal.Lett. 42 (2010) 570581.

30. R.A. Shaalan, T.S. Belal, Drug Testing and Analysis 2 (2010) 489-493.

31. S.R. Dhaneshwar, N.G. Patre, M.V. Mahadik, Chromatographia 69 (2009) 157-161.

32. E.E. Sideris, G.N. Valsami, M.A. Koupparis, P.E. Macheras, Eur. J. Pharma. Sci. 7 (1999) 271-278.

33. M.S. Stanley, K.L. Busch, A. Vincze, Planar Chromatogr. Mod. TLC 1 (1988)

34. M. Shamsipur, F. Mizani, M.F. Mousavi, N. Alizadeh, K. Alizadeh, H. Eshghid, H. Karami, Anal. Chem. Acta 589 (2007) 22-32.

35. X. Ji, B. Jin, J. Ren, J. Jin, T. Nakamura, J. Electroanal. Chem. 579 (2005) 25-31.

36. W. Peng, E. Wang, Anal. Chem. Acta 281 (1993) 663-671.

37. H.J. James, G. Carmack, H. Freiser, Anal. Chem. 44 (1972) 856-857.

38. M. Bender, M. Komiyama, In Cyclodextrin Chemistry, Springer: Berlin, Hiedelberg, Germany, 1978.

39. S.S.M. Hassan, S.A. Marzouk, Talanta 41 (1994) 891-899. 
40. T.S. Ma, S.S.M. Hassan, Organic Analysis Using Ion Selective Electrodes, Academic Press, London, UK 1982 Vols. 1 and 2.

41. J.E. Davies, G.J. Moody, W.M. Price, J.D.R. Thomas, Lab. Pract. 22 (1973) 20-24.

42. IUPAC Analytical Chemistry Division, Commission on Analytical Nomenclature, Pure Appl. Chem. 72 (2000) 1851.

43. R.M. Wightman, Analytical Chemistry 53 (1981) 1125A-1134A.

44. A.M. Bond, Analyst 119 (1994) 1R-21R.

45. A. El-Kosasy, S. Maissa, El-R. Mohamed, Chem. Pharm. Bull. 56 (2008) 753-757.

46. T.E. Edmonds, Anal. Chim. Acta 175 (1985) 1-22.

47. C. Mustafa, V.L. Nicholay, M.S. Fred, A.T. Christopher, J.S. Micheal, Sens. Actuators B 92 (2003) 171-178.

48. P.K. Samuel, S. Kimio, K. Toshiyuki, I. Takashi, S. Toshio, J. Membr. Sci. 230 (2004) 171-180.

49. S. Fink, F.C.J.M. Veggel and D.N. Reinhoudt, Adv. Mater. 12 (2000) 13151328.

50. V.S. Vasantha, K.L.N. Phani, J. Electroanal. Chem. 520 (2002) 2283-2288.

51. S.S. Hassan, M.M. Amer, S.A. Abd El-Fatah , A.M. El-Kosasy, Talanta 46 (1998) 1395-1403.

52. B.A. Conway, Ion Selective Electrodes, Ottawa Press, 3 (1995) 41. 